\title{
Agranulocytosis secondary to clozapine: a descriptive study in chilean patients
}

\author{
Abstract \\ Introduction: Agranulocytosis is one of the most serious adverse effects of clozapine. \\ The Latin American literature is currently scarce on the subject. \\ Objective: To describe the occurrence of agranulocytosis or leukopenia secondary to \\ clozapine and its associated factors in a sample of Chilean patients between the years \\ 2011-2016. \\ Materials and methods: An observational, retrospective type of study was designed \\ base on virtual information from the National Pharmacovigilance Registry and \\ definition of alarm levels according to the Technical Standard of clozapine, later \\ performing statistical analysis.
}

Results: total n 60patients, 8patients with some alarm event; Alarm I:5; Alarm II: 1; Alarm III: 2. Alarms were distributed between week 1 and week 242. The incidence was higher between weeks 0 and $12(1.26 \%)$. Until week 18, 53\% of alarms I and $100 \%$ of alarms III occurred, alarm II occurred in month 10.

Discussion: When comparing patients with and without alarm, significant differences were found in the basal count of leukocytes and neutrophils, with no differences in age and sex. Patients who presented alarms and/or lower baseline leukocyte or neutrophil counts could eventually benefit from a longer weekly follow-up. Conclusion: This study constitutes the first step towards exploring the adverse effects profile of clozapine in Chilean patients.

Keywords: clozapine, agranulocytosis, psychiatry, chile
Volume 9 Issue 2 - 2019

\author{
Vargas A,' Ebner M,' ${ }^{2}$ Gaete ${ }^{3}$ \\ 'Resident Psychiatry, Santiago University of Chile, Chile \\ ${ }^{2}$ Resident Internal Medicine. University of Chile, Chile \\ ${ }^{3}$ Resident Pediatrics, Major university, Chile
}

Correspondence: Matías Ebner Á, Resident Internal Medicine. University of Chile, Huérfanos \# 3255, Santiago, Chile, Tel +569 8 2890764, Email matias.ebner@mayor.cl

Received: Sepetember 19, 2017 | Published: April 25, 2019

\section{Introduction}

Clozapine is a drug in the family of atypical antipsychotics; synthesized in 1958 and introduced to the market in the $70 \mathrm{~s}$. A few years after its commercialization, in 1975 in Finland, the report was made regarding the appearance of agranulocytosis in 17 of the 2660 patients who received this treatment, 8 of them died product of infections associated with neutropenia, therefore, the laboratory decided to remove it from the market. ${ }^{1}$ In 1988, Kane et al, carried out a study that confirmed the effectiveness of clozapine in the treatment of refractory schizophrenia, ${ }^{2}$ as well as its safety if patients underwent monitoring of granulocyte counts; ${ }^{3}$ so in 1990 the drug was re introduced to the market in the United States.

In international studies, it is estimated that the incidence of agranulocytosis varies between 3.8 and $8 \%,{ }^{4}$ with an accumulated annual risk of $0.8 \%$ to $1.5 \% .^{5}$ Most cases occur during the first six months of treatment (84\%). The occurrence of leukopenia in patients treated with clozapine is more frequent in women, as well as in older patients, ${ }^{5}$ as reported by the international literature.

In Latin America, evidence regarding haematological adverse reactions (RAH) to clozapine is scarce. In 2015, an Argentine study was published, which included the analysis of 378 cases of RAH, using data obtained from the national pharmacovigilance system (ANMAT). These researchers found that the annual rate of leukopenia in their patients was 0.19 , while that of neutropenia was 0.38 per 100,000 treated individuals per year. The risk factors identified were: female sex, older age and use of other psychotropic drugs concomitantly. Mortality associated with agranulocytopenia was 4.2 per 100,000 treated individuals per year, which corresponds to a rate significantly higher than that reported in other regions of the planet. ${ }^{6}$ In Chile, there is a work published in 2012, which included 47 patients between 10 and 17 years, finding that the most frequent adverse reaction corresponded to sedation (76\%), while the nonspecific decrease of neutrophils reached $17 \%$, alarm I $15 \%$, alarm II $2 \%$ and alarm III $2 \% .^{7}$ In this study, the factors associated with the occurrence of alarm were not characterized.

Despite this associated risk, clozapine is one of the most powerful pharmacological tools for psychiatry, being today the standard treatment of refractory psychoses to other drugs, alone or in combination with electroconvulsive therapy (which represent between 30 and $60 \%$ of patients with schizophrenia). ${ }^{8}$ The objective of this study is to identify factors associated with the appearance of leukopenia and/or agranulocytosis in patients treated with clozapine in a Health Service of the Metropolitan Region of Santiago de Chile between 2011 and 2016.

\section{Method}

\section{Selection of the sample}

This study is observational, retrospective. The sample was selected with the following inclusion criteria: patients admitted to the clozapine pharmacovigilance system between the first of January 2011 and the first of April 2016, registered in the Health Service of 
the Metropolitan Region of Chile and who had a follow-up of at least 18 weeks, except in cases of alarm III that were considered all cases without considering follow-up extension (alarm levels explained in the next topic). It was established as the start date of January 2011, since since that year the National Pharmacovigilance Registry is available as a virtual platform. We excluded those patients admitted outside the period established in this investigation, those who did not correspond to the selected geographical area and those patients who did not reach a minimum of 18 weeks of follow-up without having presented an AHR that will explain the discontinuation of the treatment.

The research work was authorized by the hospital ethics committee in which the patients included in this study are treated, being able to access the personal data, information provided by the hemogram and the clinical file in the specific cases of the patients who presented some level of alarm, keeping confidentiality at all times.

\section{Definition of alarm events}

To evaluate RAH, the hemograms entered in the pharmacovigilance virtual platform were reviewed from the patient's admission until August 1, 2016. The leukocyte and neutrophil counts established by the Technical Norm of Clozapine, issued by the Ministry of Health of Chile in 2000 (Table 1). ${ }^{9}$

Table I Definition of alarm events

\begin{tabular}{lll}
\hline Alarm & Leukocytes $(\mathbf{m m} 3)$ & Neutrophils $(\mathbf{m m} 3)$ \\
\hline I & $3000-3499$ & $1500-2000$ \\
II & $2000-2999$ & $1000-1499$ \\
III & Bajo 2000 & Bajo 1000
\end{tabular}

\section{Analysis of data}

The data were anonymized assigning to each patient a code consisting of the initials of the first name and first surname, plus the last two digits of the RUT in order to preserve patient confidentiality. Regarding the statistical analysis, we considered the sample size with a confidence interval of $90 \%$; to compare means in relation to age and count of leukocytes and neutrophils with respect to patients who presented or not alarms, the Welch t-test was used. To establish statistical significance among various clinical variables regarding the occurrence of alarms odd ratios (OR) were calculated, with a Fisher test. The Prism 7 software was used.

\section{Results}

According to the National Registry, currently in Chile approximately 4500 patients are in treatment with clozapine, of which 230 are registered in the geographical area selected for this study $(5.1 \%$ of the national total). After applying the inclusion and exclusion criteria, the final $\mathrm{n}$ was 60 patients (maximum margin of error of $10.9 \%$, confidence level of $90 \%$ ). The characteristics of the sample are presented in Table 2.

\section{Occurrence of alarm events}

Of the selected patients, 8 presented (4.8\%) some alarm event; 5 patients $(3 \%)$ presented at least one alarm I, 1 patient $(0.6 \%)$ presented an alarm II and 2 patients (1.2\%) presented an alarm III. Of the 8 patients who presented some alarm event, $3(37.5 \%)$ presented more than one event. As an exceptional case, it should be mentioned that a male patient presented 8 alarm I events and one alarm II during a follow-up period of 252 weeks; being the first alarm I in the sixth week of follow-up and the last recorded in week 242. Table 3 shows the average dose, weeks of treatment and age of patients in their first episode of alarm.

Table 2 Variables studied in patients with and without alarm events

\begin{tabular}{llll}
\hline Variable & $\begin{array}{l}\text { Patients } \\
\text { without alarm } \\
(\mathbf{n}=\mathbf{5 2})\end{array}$ & $\begin{array}{l}\text { Patients } \\
\text { with alarm } \\
(\mathbf{n}=\mathbf{8})\end{array}$ & $\begin{array}{l}\text { Total } \\
\mathbf{( N = 6 0 )}\end{array}$ \\
\hline & Women $(\mathrm{n}=23)$ & Women $(\mathrm{n}=2)$ & $42 \%$ \\
Sex & Mens $(\mathrm{n}=29)$ & Mens $(\mathrm{n}=6)$ & Mens $(\mathrm{n}=35)$ \\
& & & $58 \%$ \\
$\begin{array}{l}\text { Edad al } \\
\text { comienzo del }\end{array}$ & $23,5 \pm 1,8$ & $25,6 \pm 5,7$ & $23,8 \pm 12$ \\
$\begin{array}{l}\text { tratamiento } \\
\text { (años) }\end{array}$ & & & \\
$\begin{array}{l}\text { Rango de } \\
\text { tiempo en }\end{array}$ & & & \\
$\begin{array}{l}\text { seguimiento } \\
\text { (semanas) }\end{array}$ & $(21-282)$ & $(8-277)$ & $(8-282)$ \\
$\begin{array}{l}\text { Promedio de } \\
\text { tiempo en } \\
\text { seguimiento } \\
\text { (semanas) }\end{array}$ & $127 \pm 12$ & & \\
\hline
\end{tabular}

Table 3 Description of variables in the first alarm event

\begin{tabular}{llll}
\hline Variable & $\begin{array}{l}\text { First alarm } \\
\text { event I } \\
(\mathbf{n = 6})\end{array}$ & $\begin{array}{l}\text { First alarm } \\
\text { event II and } \\
\text { III } \\
(\mathbf{n}=\mathbf{3})\end{array}$ & $\begin{array}{l}\text { First alarm } \\
\text { event } \\
(\mathbf{n}=\mathbf{8})\end{array}$ \\
\hline $\begin{array}{l}\text { Average dose }(\mathrm{mg} / \\
\text { day) }\end{array}$ & $187 \pm 51$ & $300 \pm 0$ & $216 \pm 4 \mid$ \\
& & $(6-11)$ & $(1-187)$ \\
$\begin{array}{l}\text { Weeks until the } \\
\text { event }\end{array}$ & $(I-187)$ & $19 \pm 10$ & $28 \pm 23$ \\
\end{tabular}

Age at the time of

$26 \pm 6$

$37 \pm 14$

$27 \pm 5$

\section{Dosage of clozapine and occurrence of alarms}

Taking all the alarm events into account, the average dose was $251 \pm 26 \mathrm{mg} /$ day of clozapine. Both alarms III and alarm II occurred with doses of $300 \mathrm{mg} /$ day. 5 of the 8 patients who presented alarm $(62.5 \%)$ presented it for the first time receiving $300 \mathrm{mg} /$ day of clozapine.

\section{Description of alarm events III}

Of the two alarm III events observed, one occurred in week 7 and the other in week 11. Both corresponded to male patients, both 
patients presented sedation, tachycardia and nonspecific neurological symptoms during the first 4 weeks of treatment (syndrome confusional and dysarthria), of which a cause could not be identified. None of the two patients presented another RAH event prior to alarm III. Both presented an increase in the neutrophil count in the third week of treatment, and then a sustained drop of these until the alarm was presented. Other haematological adverse reactions of the 60 patients, 8 had leukocytosis at some point in the follow-up (13.3\%), 7patients had eosinophilia (11.6\%), 6 patients had thrombocytopenia (10\%), 5 patients had thrombocytosis $(8.3 \%)$ and 2 patients presented anemia $(3.3 \%)$.

\section{Temporary distribution of alarm events}

The occurrence of alarms was distributed between week 1 and week 242 . The incidence peaks at week 12 of follow-up. The incidence of alarm events was $1.1 \%$ at the 6 th week, and from $1.3 \%$ at the 12 th week. Up to week 18 there had been 10 of the 20 alarm events (50\%) observed in the follow-up period, including both alarms III, however alarm II did not occur until week 40.

Taking into account the occurrence of the first alarm event in each patient, in 7 of the 8 patients it occurred before 18 weeks, only one patient presented a first event outside this period (week 187). The distribution of the presentation of alarm events according to weeks of treatment is shown in Figure 1.

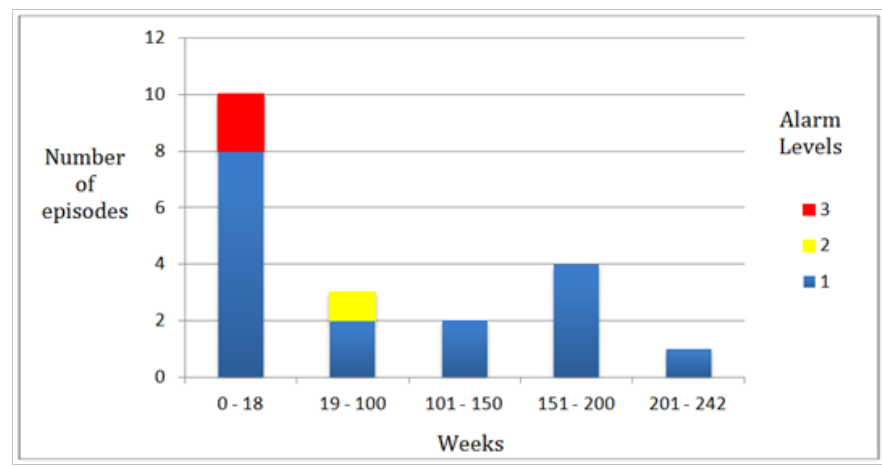

Figure I Distribution of the presentation of the different alarm levels according to the weeks of treatment with clozapine $(n=20)$.

Relationship between clinical variables and the occurrence of an alarm event. A comparison of different variables was made between the group of patients who presented at least one alarm event $(\mathrm{n}=8)$ and those who did not $(n=52)$. The results are shown in Table 4 .

Table 4 Comparison between age, baseline neutrophil count and baseline leukocyte count between patients with alarm and patients without alarm

\begin{tabular}{|c|c|c|c|}
\hline Variable & $\begin{array}{l}\text { Patients with } \\
\text { alarm }\end{array}$ & $\begin{array}{l}\text { Patients } \\
\text { without alarm }\end{array}$ & $\begin{array}{l}\text { Statistically } \\
\text { significant } \\
\text { difference }\end{array}$ \\
\hline Age & $23,5 \pm 1,8$ & $25,6 \pm 5,7$ & No $(p=0,31)$ \\
\hline $\begin{array}{l}\text { Baseline } \\
\text { leukocyte } \\
\text { count }\end{array}$ & $6063 \pm 292$ & $98 \mid 1 \pm 1314$ & Si $(p<0,000$ I $)$ \\
\hline $\begin{array}{l}\text { Baseline } \\
\text { neutrophil } \\
\text { count }\end{array}$ & $5825 \pm 764$ & $3365 \pm 309$ & $\mathrm{Si}(p<0,000 \mathrm{I})$ \\
\hline
\end{tabular}

Likewise, we estimated the probability of presenting an alarm in relation to the female sex variable, having presented leukocytosis, having presented eosinophilia and having presented some other event of RAH, the Odds Ratio calculated had no statistical significance. Results are shown in Table 5.

Table 5 OR of clinical variables regarding the occurrence of alarms

\begin{tabular}{lll}
\hline Variable & $\begin{array}{l}(\mathbf{9 5 \%} \text { confidence } \\
\text { interval) }\end{array}$ & $\begin{array}{l}\text { Statistical } \\
\text { significance }\end{array}$ \\
\hline Female sex & $0,4(0, I-1,9)$ & NO $(\mathrm{P}=0,44)$ \\
$\begin{array}{l}\text { Having presented } \\
\text { leukocytosis }\end{array}$ & $\mathrm{I}, \mathrm{I}(0, \mathrm{I}-8, \mathrm{I})$ & $\mathrm{NO}(\mathrm{P}>0.99)$ \\
$\begin{array}{l}\text { Having presented } \\
\text { eosinophilia. }\end{array}$ & $4,0(0,2-36,7)$ & $\mathrm{NO}(\mathrm{P}=0,32)$ \\
$\begin{array}{l}\text { Having submitted any } \\
\text { other RAH }\end{array}$ & $\mathrm{I}, \mathrm{I}(0,2-5,6)$ & $\mathrm{NO}(\mathrm{P}>0,99)$ \\
\hline
\end{tabular}

\section{Discussion}

Despite the known effectiveness of this drug, series have established that less than $25 \%$ of patients with schizophrenia refractory to treatment are clozapine users, ${ }^{10}$ this scenario being their main indication given the varied clinical benefits shown in this study. ${ }^{11}$ That is why it is important to encourage its use in the indicated cases following a strict follow-up protocol.

Regarding the variables that could influence the occurrence of alarms, contrary to that cited in the literature, ${ }^{6,12}$ the female sex was not statistically significant. Likewise, the presence of eosinophilia was not statistically significant as a predictor of the occurrence of alarm, a finding similar to that found in another US article..$^{13}$ A greater incidence of RAH has been described with the concomitant use of clozapine with other potentially myelosuppressive drugs; variable not studied in this study but to be considered in clinical practice. ${ }^{14}$ When analyzing the group of patients who presented an alarm event, excluding patients who presented alarm III and therefore discontinued the drug, 3 of the 6 patients presented a new alarm event during followup $(50 \%)$. The count of leukocytes and neutrophils prior to the start of treatment was significantly lower in those patients who subsequently presented alarm, which is a finding that could be useful in planning the follow-up of patients who start treatment with clozapine.

It was evidenced that most of the alarm events occurred before week 18 of treatment, this finding was coincident with that found in other registries. ${ }^{12,15}$ The average dose of clozapine with which the appearance of the first alarm event occurred was $216 \pm 41 \mathrm{mg} /$ day, variable not found in the literature for comparison but useful in the clinic to estimate the time of greatest risk of alarm.

Regarding alarm II, it was presented in the tenth month of followup, in a patient who had already presented multiple alarm events I. There is no record of a sustained decline in neutrophil count, since the patient was in the phase of monthly control. In addition, among the patients who presented alarm I, most of them had an event again. This could be an indicator of the need to prolong weekly control in patients who have already presented an alarm event and/or have lower leukocyte or neutrophil counts at the beginning of treatment, as stipulated in some international guidelines. ${ }^{16-19}$ Unlike the study 
conducted in Argentina, there were no deaths secondary to RAH to clozapine during the follow-up period. ${ }^{6}$

It should be mentioned that the virtual pharmacovigilance platform is not designed to carry out this type of studies. In addition, it does not have a record of non-haematological adverse reactions so it is not possible to perform an analysis considering these data, which is of special relevance since in the studies published in the last 10years special interest has been placed on the adverse effects of clozapine such as myocarditis with an estimated incidence of $1.2 \%,{ }^{19}$ deep vein thrombosis, ${ }^{20}$ weight gain, ${ }^{21,22}$ alterations in glucose metabolism ${ }^{23}$ and constipation; ${ }^{24}$ The knowledge of these complications has led to an increase in the number of studies performed on patients taking this drug, in order to improve their health and quality of life.

Another limitation of this study was the reduced number of included patients (out of a total of 230 patients, to have had a confidence interval of $95 \%$, the sample size should have been 145 patients vs. 60 patients included in this study), this is determined mainly by the characteristics of the available registry, the inclusion criteria used and the ethical limitations that regulate access to patient data from other health services. This could be improved by carrying out a study conducted by teams from multiple centers, designing a study of a different methodology that ideally is prospective, recruiting patients upon admission to the pharmacovigilance program. Carrying out a case - control study, randomizing two groups of patients. This could be done in a group intervention with a modified program based on current international recommendations, while with the other group continue with the current established strategy (control), and then analyze the different results obtained. This study corresponds to a first step towards exploring the profile of clozapine RAH in Chilean patients.

Finally, taking into account that the National Standard that regulates the indication of clozapine was drafted in 2000 . We believe that given the continuous advances and new monitoring strategies evidenced in international studies, it would be very useful to update them to improve the safety profile of clozapine in our country.

\section{Conclusion}

This study constitutes the first step towards exploring the adverse effects profile of clozapine in Chilean patients.

\section{Acknowledgments}

None.

\section{Conflicts of interest}

Author declare their are no conflicts of interest towards the article.

\section{References}

1. De Fazio P, Gaetano R, Caroleo M, et al. Rare and very rare adverse effects of clozapine. Neuropsychiatr Dis Treat. 2015;11:1995-2003.

2. Kane J, Honigfeld G, Singer J, et al. Clozapine for the treatment-resistant schizophrenic. A double-blind comparison with chlorpromazine. Arch Gen Psychiatry. 1988;45(9):789-796.

3. Lieberman JA, Kane JM, Johns CA. Clozapine: guidelines for clinical management. J Clin Psychiatry. 1989;50(9):329-338.

4. Cohen D, Bogers JPAM, van Dijk D, et al. Beyond white blood cell monitoring: screening in the initial phase of clozapine therapy. $J$ Clin Psychiatry. 2012;73(10):1307-1312.
5. Alvir JM, Lieberman JA, Safferman AZ, et al. Clozapine-induced agranulocytosis. Incidence and risk factors in the United States. $N$ Engl J Med. 1993;329(3):62-67.

6. Balda MV, Garay OU, Papale RM, et al. Clozapine-associated neutropenia and agranulocytosis in Argentina (2007-2012). Int Clin Psychopharmacol. 2015;30(2):109-114.

7. Boehme K V, Durán L E. Clinical experience with the antipsychotic clozapine in children and adolescents under 18 in Chile. Rev Chil NeuroPsiquiatr. 2012;50(2):85-99.

8. Solanki RK, Singh P, Munshi D. Current perspectives in the treatment of resistant schizophrenia. Indian J Psychiatry. 2009;51(4):254-260.

9. Ministry of Health. Technical Standard for the Clinical Use of Clozapine. Division of People's Health, Mental Health Unit of the Ministry of Health; 2000

10. Gören JL, Rose AJ, Smith EG, et al. The Business Case for Expanded Clozapine Utilization. Psychiatr Serv. 2016;67(11):1197-1205.

11. Williams R, Malla A, Roy M, et al. What Is the Place of Clozapine in the Treatment of Early Psychosis in Canada? J Psychiatry. 2016;62(2):109 114.

12. Lau K, Yim P. Neutropenia and Agranulocytosis in Chinese Patients Prescribed Clozapine. East Asian Arch Psychiatry. 2015;25(4):164-167.

13. Ames D, Wirshing W, Baker R, Umbricht D. Predictive value of eosinophilia for neutropenia during clozapine treatment. J Clin Psychiatry. 1996;57(12):579-581.

14. Urban A, Wiglusz M, Cubala W, et al. Rapid-onset agranulocytosis in a patient treated with clozapine and lamotrigine. Psychiatr Danub. 2015; 27(Suppl 1):S459-S461.

15. Armendariz E. Clozapine: a historical view and current role in treatmentresistant schizophrenia. Ars Pharm. 2008;49(2):135-144.

16. https://www.clozapinerems.com/CpmgClozapineUI/home.u

17. ABUHB Mental Health. Protocol for the Use and Administration of Clozapine. UK: Aneurin Bevan University Health Board; 2015.

18. Manchester Mental Health and Social Care Trust. Clozapine Guideline Community. UK: Manchester City Council; 2014

19. Haas SJ, Hill R, Krum H, et al. Clozapine-associated myocarditis: a review of 116 cases of suspected myocarditis associated with the use of clozapine in Australia during 1993-2003. Drug Saf. 2007;30(1):47-57.

20. Paciullo CA. Evaluating the association between clozapine and venous thromboembolism. Am J Health Syst Pharm. 2008;65(19):1825-1829.

21. Bai YM, Lin CC, Chen JY, et al. Association of initial antipsychotic response to clozapine and long-term weight gain. Am $J$ Psychiatry. 2006;163(7):1276-1279.

22. Simon V, van Winkel R, De Hert M. Are weight gain and metabolic side effects of atypical antipsychotics dose dependent? A literature review. $J$ Clin Psychiatry. 2009;70(7):1041-1050.

23. Henderson DC, Cagliero E, Copeland PM, et al. Glucose metabolism in patients with schizophrenia treated with atypical antipsychotic agents: a frequently sampled intravenous glucose tolerance test and minimal model analysis. Arch Gen Psychiatry. 2005;62(1):19-28.

24. Shirazi A, Stubbs B, Gomez L, et al. Prevalence and Predictors of Clozapine-Associated Constipation: A Systematic Review and MetaAnalysis. Int J Mol Sci. 2016;17(6).pii: E863. 